\title{
What's Your Story? Using Interviews and Narrative in Academic Research
}

\author{
Jonny H. Bahk-Halberg* \\ Associate Professor, Department of English Interpretation \& Translation, Hankuk University of Foreign \\ Studies, Seoul, Korea \\ *Corresponding Author: Jonny H. Bahk-Halberg, Associate Professor, Department of English \\ Interpretation \& Translation, Hankuk University of Foreign Studies, Seoul, Korea
}

\begin{abstract}
While there are numerous ways of researching L2 learners to find out how best to help them learn and grow, one of the most obvious, and most neglected, is to simply ask them what they did and what they think about what they did. Interview and narrative research are two of the most useful implements in the qualitative researcher's methodological toolkit.
\end{abstract}

Keywords: Interviewing, Narrative Research, Qualitative Inquiry, Language Teacher Education

\section{INTRODUCTION}

There are myriad methods for finding answers when conducting research. Quantitative methods dealing with statistics and numbers may be best for solving some problems, while others are best addressed using qualitative methods such as text analysis, focus groups, and questionnaires. While it is true that a former journalist (like me) may be biased in his selection of methodological tools, I was struck long ago by a line I read by renowned Danish educational psychologist and research scholar Steinar Kvale: "If you want to know how people understand their world and their life, why not talk with them?" (1996, p.1).

\section{Culture and Narrative}

A strong influence on my thinking about what kind of knowledge interview and narrative research may bring to the field comes from rereading Second Language Learning as Participation and the (Re)construction of Selves byPavlenko and Lantolf (2000). The authors draw on the ideas of Bakhtin, Bruner, Rorty, Polkinghorne, and others to make the point that learning a second language is not simply acquiring the grammar, vocabulary and pronunciation of a new communicative code, but a long-term struggle to enter another cultural world.

Pavlenko and Lantolf note that, language is more than simply accumulating the building blocks of a new language, as it has a lot to do with involvement with a new language community and culture. They say that it is at least as much about participation in that new community as it is about acquisition of a set of skills. To study second-language acquisition in terms of participating in a new language community - language socialization - they suggest that we need to consider first-person narratives as a rich source of data.

Pointing to the "increasing stature" (Pavlenko\&Lantolf, 2000, p.159) of personal narratives in the social sciences similar to this study, they suggest that much can be learned from language participants about acquiring a second language. Still, they concede that "narrative knowing" has not attained the acceptance level of experimental/observational methods which have resulted in so many great achievements in the hard sciences. They write:

We find it difficult to dispute Polkinghorne's (1988) incisive, although we suspect, for some, controversial observation, that the social sciences have not manifested the same level of accomplishments as the hard sciences, despite nearly a century-long love affair with their methodology and discourse(Pavlenko\&Lantolf, 2000, p.159).

They strengthen the point by quoting Polkinghorne directly: 
I do not believe that the solutions to human problems will come from developing even more sophisticated creative applications of the natural science model, but by developing additional, complementary approaches that are especially sensitive to the unique characteristics of human existence. (Polkinghorne 1988: x).

While I have at times been slightly uncertain about how much I can learn from just talking to students about their experiences, again referring to my journalistic experience, it has always made sense to me to learn about a phenomena by asking those directly involved in it. In addition, rereading Pavlenko and Lantolf persuaded me that simply asking people about themselves, what they do, how they learned, and what it means to them, is valid.

Referring to Bruner's words from his 1996 work, The Culture of Education, Pavlenko and Lantolf write:

Jerome Bruner, one of the founders of modern cognitive psychology, recognizes that the doxology of the scientific method - 'thou shalt not indulge self-delusion, nor utter unverifiable propositions, nor commit contradiction, nor treat mere history as cause' - is unable to describe the basis on which ordinary people go about making sense of their and others' activities. The problem, in Bruner's view, is that the ways in which people make sense of their experiences and themselves as 'testable propositions'. Consequently, the quest for the causes of human sense making itself makes little sense, and therefore, the logico-scientific mode ofconducting research requires a complementary mode - a mode that searches for reasons rather than causes (Pavlenko\&Lantolf, 2000, p. 158).

My projects often seem to be a perfect fit for the description written by Pavlenko and Lantolf, as they, and I, interpret the ideas of Bruner (1986, 1990, 1996, \& 2002) and Polkinghorne (1988). I agree with Polkinghorne that answers to the big questions are more likely to come from new ways of asking questions involving human participation rather than from using the old tools of scientific investigation in more sophisticated ways.

\section{NARRATIVE/INTERVIEW RESEARCH}

"(T)he interview is neither an objective nor a subjective method - its essence isintersubjective interaction." (Kvale, 1996, p. 66)

I think there are more important reasons than statistical skepticism to be leery of using numerical data in studying how Korean students go through the process of learning spoken and written English. Certainly there are areas where statistical data and numbers can be useful, but as Polkinghorne said in his landmark book, Narrative Knowing and the Human Sciences (1988), "I find that our traditional research model, adapted from the natural sciences, is limited when applied in the study of human beings" (p. x). Polkinghorne strongly suggests that in his field, psychology, practitioners working with human data, people's stories, had a better understanding of the way things were and what needed to be done than researchers using more "scientific," positivist approaches.

I think it is easy to make the same arguments that Polkinghorne (1988) did about the human sciences when researching in almost any educational setting, and my projects often seembetter fitted to an approach in which the researcher asks experts, in this case language learners themselves. how they went about getting as far as they have, and what has led them to continue in pursuit of their language learning goals. I want to learn from what my subjects can tell me, rather than analyze them as bits of data. Of course, not every answer from a student about how they learn, or a professional about what led them to their career skills and interests, will render the ultimate truth. But I think the answers I got from students and professionals make up pieces of that ultimate truth, just as a chip of colored glass, useless by itself, is an integral part of the pattern of an elaborate stained glass window. It certainly seems that if one wants to know how someone went through the process of learning to do something, asking them directly would be a good way to go, and the first one I would choose.

The type of research interview I often use has been defined in various ways, but the one I prefer is "an interview whose purpose is to obtain descriptions of the life world of the interviewee with respect to interpreting the meaning of the described phenomena" (Kvale, 1996, p. 5-6). While I attempt to make my interviews to be as open-ended as possible, with my conversation partners having a lot of autonomy in what they say to help me understand their world, the interviews are based on my ideas and my curiosity about their world as starting points. I attempt to make the interviews as close to 
informal conversations as possible, but Kvale reminds me that " $(\mathrm{t})$ he research interview is not a conversation between equal partners, because the researcher defines and controls the situation" by introducing a topic and asking follow-up questions to probe for more meaning (Kvale, 1996, p. 6). However, he argues that this human touch, the subjectivity of interview conversations as research is a strength, not a weakness, because humans are uniquely capable of catching nuances of meaning and differences of opinion in how those being interviewed see a phenomenon and in communicating a message or painting a picture of "a manifold and controversial human world" (Kvale, 1996, p. 7).

Mishler (1986) notes that variations within the questions, or the way questions are asked, can have great effect on the answer that will be received. From my experience as a journalist asking questions, and from my experience in the classroom working with Korean students, I can appreciate his warning. Differences in tone, register, politeness, and manyother variables that might lead the respondent to try to provide the answer the interviewer is looking for would defeat the purpose of this study. While I understand that complete objectivityor neutrality is beyond human reach, I strive throughout my questioning, whether on paper, by email, or in person, to be a friendly, positive, interested scholar, not using what I think are leading or loaded questions while providing as much encouragement as I can to respondents to talk about themselves fully and freely. Asking open-ended, "answerable" questions is a skill I developed a knack for in my newspaper days. I find it important to put myself in the respondent's shoes mentally and think about how possible, or easy, or comfortable it is to answer a question. If it works for me, seems to get the right answer to lead toward my point, and "feels" answerable, I use it. While I tend, in most studies, to use fairly open-ended questioning techniques, trying to follow the thread of conversations as I talk to my partners about their experiences in becoming and being proficient English communicators, that does not mean I go into an interview without a clear idea of the areas I want to learn about and the potential questions I will ask.

Despite the fact that I grew up in what has been called an "interview society' inwhich interviews seem central to making sense of our lives" (Silverman, 2000, p. 822), I don't really think I understood the information-gathering possibilities and pitfalls until I worked as a journalist for several years. Of course, not everything learned in interviews is the pure, unvarnished truth. However, I couldn't imagine a more efficient way of findingout what I want to know, from the likelihood of a labor strike to the meaning of a complex economic phenomenon, than calling an expert who already has the background knowledge I lacked, in these examples a knowledgeable labor organizer or economics professor or two. While it also made sense to go out and do some learning about the issue when time was available, at a few minutes before deadline, when there was a missing element of information in a news story, there was no better way to find out the information I needed than to get on the phone and ask someone who knew the answer -- fast.

Certainly there are factors to beware of with this fast and easy approach. I soon learned not to be shy when asking a major executive the questions many readers were curious about - "what enquiring minds want to know," to recall an old advertisement for a well-known gossip news tabloid - for example, what was his or her annual income? I learned to do this not because I am naturally nosy and aggressive (well, perhaps a little), but because I quickly found that when I omitted the questions everyone was curious about, they were the first things my editors wanted to know when I wrote up the story. I also learned, almost as quickly, not to expect that answers to probing questions would always be truthful. I think this experience has served me well, and while today I would say I am skeptical rather than cynical, that too, is a subjective (qualitative?) judgment call. While I am sure working for newspapers taught me not to shy away from tough questions, I think it also taught me to do enough homework and not to believe everything I heard. Despite the currently poor reputation that journalism has in the U.S., I don't think I came out of the experience an inhumane human being.

Sociologist and mass media pioneer Paul Lazarsfeldis cited by Mishler as one who understood in 1935 that "variability in how interviewers ask questions is the key to good interviewing and not a problem to be solved by standardization (Mishler, 1986, p. 22). While I am sometimes not so sure I can spell out precisely why certain question types seem to work better in some situations than others, after more than a decade as a journalist, andmore than twice that much time spent trying to encourage reluctant Korean and other non-English speakers to "open up" in class, I have a lot of experience at finding ways to encourage people to talk.

One method worthy of mention - simply keeping quiet - is sometimes left out of guidance to interviewers. I was glad to see that Kvale included it in his seminal work on research interviewing 
(1996). Silence really can be golden, particularly during an interview. Often I've found the best way to get people to talk is to not ask too many questions, but to just sit quietly and give time to come up with an answer. I agree with Kvale when he wrote about "silence" as one type of interview question:

Rather than making the interview a cross examination by continually firing off questions, the research interviewer can take a lead from therapists in employing silence to further the interview. By allowing pauses in the conversation the subjects have ample time to associate and reflect and then break the silence themselves with significant information (Kvale, 1996, p. 134).

In addition to Kvale's explanation, I also think that silence in conversation, as is also encouraged by those who talk about extending "wait time" in ESOL instructional settings,puts some gentle pressure on those on the answering side of the research conversation. Silence can be tough to take, particularly for those accustomed to American or Western conversational style. While I think I've become very comfortable with silence and "waiting out" students or conversation partners, I also confess I at times needed to guard against using it in ways that would have equally made the interview feel like a crossexamination.

\section{More on NARRATIVE}

A truly skilled academic writer can make learning and research seem interesting and easy. While it may be because of his subject matter, telling stories, it seems that Gian Pagnucci did just that in his book on narration. From where I sit as I wrIte these words at my desk in Seoul, looking at projects before me, his words certainly seem to lighten my load: "What if, instead of telling doctoral students, "Look for a gap in the research," we said, "Look for a story that needs to be told"? (2004, p. 22).

I am intrigued by Pagnucci's idea of looking for untold stories. After all, especially in qualitative research, almost any topic can be a new way of looking at a research problem, if things haven't been done in exactly that way before. Pagnucci seems to put it another way that makes more sense, simply and understandably, similar to the way that telling stories makes simple, understandable sense to people, both as they listen and as they talk.

As I continue to read about talking to people, listening to their stories and retelling my own story about their stories, I often realize that I set up major tasks for myself. It is tough enough to design a study that is reliable, valid, objective and replicable. However, in interview or narrative research studies, that would mean taking the standards of the quantitative paradigm and trying to make them apply to qualitative research, an impossible task (Altheide\& Johnson, 1998). Instead, I need to not only do the research, but also write a good story, narrative scholars say. Lieblich, Tuval-Mashiach, and Zilber (1998) list seven criteria for evaluating narrative research, originally proposed by psychobiographer Willam McKinley Runyan in 1984, and they seemed when first encountered, a challenging list. The criteria are:

- Providing insight into the person, clarifying the previously meaningless orincomprehensible, suggesting previously unseen connections;

- Providing a feel for the person, conveying the experience of having known or met him or her;

- Helping us to understand the inner or subjective world of the person, how he or shethinks about their own experience, situation, problems, life;

- Deepening our sympathy or empathy for the subject;

- Effectively portraying the social and historical world that the person is living in;

- Illuminating the causes (and meanings) of relevant events, experiences, and conditions; and

- Being vivid, evocative, emotionally compelling to read (Lieblich, Tuval-Mashiach, \&Zilber, 1998, p. 172)

While these criteria may go beyond my capabilities in the research projects I work on, they are certainly worth aiming for. I hope I can achieve at least some of these goals in the future. I would rather aim high and miss the mark than aim low and hit it.

The ideas in Polkinghorne's influential book, Narrative Knowing and the Human Sciences (1988), are a clear fit with what I want to do in my research projects: to simply find meaning within others' stories of their experiences in regard to their learning and development as English language learners. 
Polkinghorne writes:

Narrative is a form of "meaning making." It is a complex form which expresses itself by drawing together descriptions of states of affairs contained in individual sentences into a particular type of discourse. This drawing together creates a higher order of meaning that discloses relationships among the states of affair. Narrative recognizes the meaningfulness of individual experiences by noting how they function as parts in a whole. Its particular subject matter is human actions and events that affect human beings, which it configures into wholes according to the roles these actions and events play in bringing about a conclusion. (1988, p. 36)

Bell also lists good reasons for using narrative inquiry, reasons that seemed a good fit with the projects I often work on:

- Narrative allows researchers to understand experience. People's lives matter, but much research looks at outcomes and disregards the impact of experience itself. ...

- Narrative lets researchers get at information that people do not consciously know themselves. Analysis of people's stories allows deeply hidden assumptions to surface. ...

- Narrative illuminates the temporal notion of experience, recognizing that one's understanding of people and events changes. ... (2002, p. 209)

My hope, no my goal, is to continually encourage my conversation partners to open up and tell me stories about their development and learning experiences, to put things in their context rather than simply answer a list of questions. While I am still a bit uncertain as to how well my stories stack up against the above criteria outlined by Runyan, I certainly look for patterns of meaning within their stories, which are spoken by the learners themselves with patterns of meaning in mind. In the results, their meanings as they interpreted them seen through my eyes, I think another layer of interpretive meaning is added to the stories. Another goal as I work with their words was not to ignore or delete any meanings in the way I filtered what they tell me of their experiences.

I am aware that in a Korean context, asking students to tell me a story may not always get the same response as in more familiar (to me) Western cultural surroundings (Gergen, 2001; Pavlenko, 2002; Scollon\&Scollon, 1995). I think this potential problem is somewhat ameliorated by the exposure to Western narrative these students have had in the current era, some by living overseas, and all of them here in Korea, where the pervasive influence of the Western-oriented world culture sometimes seems as strong as anyplace in the world because of movies, books, and other media exposure. In addition, my familiarity with Korean cultural expectations after living here for most of the last 20-plus years is a strength in terms of being able to read between the lines of what I learn from my conversation partners. And if the stories students tell me have an Asian or Korean flavor, so much the better!

I also take to heart Pavlenko's warnings "against treating narratives simply asfactual data subject to content analysis" (2002, p. 214). She emphasizes that there is good evidence showing that narratives are co-creations of the storyteller and listener, and are strongly influenced by "social, cultural, and historical conventions" (Pavlenko, 2002, p. 214).

Like Runyan, Clandinin and Connelly offered their ideas about criteria for goodnarrative and traced the development of their thoughts on the subject over time (2000, p. 184-185). From John Van Maanen's "apparency" and "verisimilitude," to Lincoln and Guba's (1985) transferability," as opposed to the more positivistic "generalizability," they note the importance of avoiding assumptions about cause-effect relationships simply because things happen one after the other in time. But they write about shifting their thinking from looking at "what makes a good narrative" to "what makes a good narrative inquiry," helping them look more closely, not only at the text itself, but also at the overall inquiry. Looked at from this direction, I was again challenged, yet also somewhat comforted, by the Zen-like answer they approached in response to their big question about narrative inquiry:

As we continue to work at the boundaries of narrative inquiry, we attempt to develop criteria that work within the three-dimensional narrative inquiry space. However, it is wakefulness that in our view most needs to characterize the living out of our narrative inquiries, whether we are in the field, writing field texts, or writing research texts and wondering about what criteria to use in a particular narrative inquiry. (Clandinin\& Connelly, 2000, p. 185) 
The word and the meaning behind it - wakefulness, "the process of paying close and continuous attention" (wakefulness, n.d.), appealed to my imagination in terms of what I want to do with research interviews: pay attention closely and continuously as my conversation partners tell me about their learning and their lives.

\section{LEARNING THROUGH INTERVIEWS}

Like Rubin and Rubin (2005), I prefer the term "conversational partner" to "subject," which sounds like a lab rat, "collaborator," which collocates in my mind after "French" and brings to mind thoughts of Nazi sympathizers in the Vichy France of World War II, or "informant," which sounds too much like a "snitch" who reports a troublemakerto the authorities, as they also note. But it's more than the term that I like. My partners inconversations most certainly help me with my research projects, at least as much as my professors or my reference materials. They agree to share with me their stories abouttheir development and learning experiences that have changed their lives and helped makethem who they are.

When Spradley writes about the "essence of ethnography" (1979, p. 4)," heexpresses the distinction this way:

Instead of collecting 'data' about people, the ethnographer seeks to learn frompeople, to be taught by them. ... Ethnographers adopt a particular stance toward people with whom they work. By word and by action, in subtle ways and direct statements, they say, "I want to understand the world from your point of view. I want to know what you know in the way you know it. I want to understand the meaning of your experience, to walk in your shoes, to feel things as you feel them, to explain things as you explain them. Will you become my teacher and help me understand?" This frame of reference is a radical departure from treating people as either subjects, respondents, or actors (Ibid. p. 34).

It seems clear to me from a number of perspectives (Allwright\& Bailey, 1991; Brown, 1988; Fanselow, 1987; Freeman, 1996; Gebhard, 1996; Gebhard\&Oprandy, 1999; Hinkel, 2001;Paley, 1990) as well as from my own classroom experience, that a teacher of language especially, whether engaged in research or not, must always be ready to learnfrom his students, much like Spradley suggested that researchers be ready to learn from their partners in research conversations. One of my favorite reminders for this idea comes from Wayne W. Dyer's 1976 book, entitled Your Erroneous Zones. There, he writes:A colleague of mine who teaches graduate courses for teachers frequently asks the old-timers, who have spent 30 years or more in the classroom, "Have you really been teaching for 30 years or have you been teaching one year, 30 times? (p. 146)

I hope I can learn a little, do something better every year, and continue to grow as a person and a teacher, rather than doing the same old thing year after year. While my conversation partners may not have been the only, or even the best sources of information on what kinds of learning and knowledge are needed to become a successful interpreter/translator, which might be better gained from their teachers or theorists who have analyzed the processes they went through, they can often provide direct, first-hand information on the learning process itself, being products who were at one time completely enculturated in the environment under study, which has long-lasting effects on the way they live now. My research projects depend on my storytelling, and also on the stories of my students. But I don't think that's too much to demand of such an essential human capacity. As award-winning storytelling teacher Vivian Gussey Paley notes, "Play and its necessary core of storytelling are the primary realities in the preschool and kindergarten, and they may well be the prototypes for imaginative endeavors throughout our lives" (1990, p. 6).

\section{Biases And ACKNOWLedging Their PRESENCE}

It seems important to me in qualitative research to understand the importance of being as upfront as possible about my biases. I agree with most qualitative researchers, who "would deny the possibility of pure objectivity in any scientific endeavor" (Hatch, 2002, p. 9). While I hope my data, evidence, and final results are to a great degree based on the empirical evidence I can gather, I also need to remember to acknowledge that I work with human instruments, both in myself and in my informants or "conversational partners" (Rubin \& Rubin, 2005, p. 14). I am a long way from a belief system, as scholars Peter Schwartz and James Ogilvy attributed to those holding a "Newtonian world view." This view would hold that as an observer I "can be isolated from experiments and the world (I am) studying to produce an 'objective' description" (Lincoln \& Guba, 1985, p. 21). Instead of dreaming 
that I can somehow be an "objective" chronicler of my students' stories, I have tried to follow the suggestions I have read to be aware of, admit to, and use my own subjectivities to help me make more out of what I heard from them. (Hatch, 2002; Lincoln and Guba, 1985; Vandrick, 1999, \& Woo, 1999).

"Who are you to do this?" asked Agar (1996, p. 91) in a chapter title, and the question is a good one. In the first sentence of that chapter, his portrayal of ethnography as "really quite an arrogant enterprise" (Ibid.) led me to some introspective thoughts about less positive things than the noblesounding "traveler" metaphor mentioned by Kvale (1996). Agar expresses concern about the "personality and cultural background of the ethnographer" (1996, p. 93), noting, "before psychoanalysts are considered competent to analyze others, they must first go through analysis themselves" (Ibid., p. 92).

This admonition, to remember that my culture, my background, my education, my personality, and my values all make me less than precise as a scientific research instrument, help me look at my own cultural interference. I think I have already looked at a lot of the "cultural baggage" I carried to Korea more than two decades ago, but I have no doubt there is so much more that I will be discovering it for the rest of my life. In teaching and communicating with Koreans, I have had many opportunities to look at what Vandrick called "A feeling of superiority of West to East, of English to other (especially non-European) languages, so that teaching English becomes a kind of preaching a 'better way' to the "natives" (1999, p. 63). Do I see the elements of my American born and bred personality (Woo, 1999) that conflict with the expectations of my Korean students, no matter how "Westernized" they may seem?

Agar's warning, the "on-the-job training" I have received in intercultural communication over the past decades, and lots of reading has helped me remember to try to take into account and try to let my readers see those facets of my personality that may have affected or interfered with my study. On the other hand, I see my interview research as being about Korean English language learners, and not just auto ethnography. How much do I need to write about my academic and career background? What about my friends and relationships in Korea? Should I go into detail about any personal issues? Which ones? These are questions that arise in my mind as I reread Agar's book, along with some personal narratives in other areas that come to mind. They are questions I continue to consider and have definitely informed my wondering and writing as my research work continues.

\section{Concluding Thought}

While there may be no perfect solution, for many research questions that simply cannot be summed up in numbers or formulae because of the "human factor," asking people questions, then interpreting and telling their stories continues to be a fitting strategy for many research problems in an imperfect world.

\section{REFERENCES}

[1] Agar, M.H. (1996). The professional stranger: An informal introduction to ethnography. New York: Academic Press.

[2] Allwright, D., \& K.M. Bailey. (1991). Focus on the classroom: An introduction to classroom research for language teachers. Cambridge: Cambridge University Press.

[3] Altheide, D.L., Johnson, J.M. (1998). Criteria for assessing interpretive validity in qualitative research. In N.K. Denzin \& Y.S. Lincoln (eds), Collecting and interpreting qualitative materials, pp.283-312. Thousand Oaks, CA: Sage

[4] Bell, J.S. (2002). Narrative inquiry: More than just telling stories. TESOL Quarterly 36, (207-213).

[5] Brown, J.D. (1988). Understanding research in second language learning. Cambridge: Cambridge University Press.

[6] Bruner, J. (1986). Actual minds, possible worlds. Cambridge, MA:Harvard University Press.

[7] Bruner, J. (1990). Acts of meaning. Cambridge, MA: Harvard University Press.

[8] Bruner, J. (1996). The culture of education. Cambridge, MA: Harvard University Press.

[9] Bruner, J. (2002). Making stories: Law, literature, life. New York: Farrar,Straus\& Giroux.

[10] Clandinin, D.J. \& Connelly, F.M. (2000). Narrative inquiry: Experience and story in qualitative research. San Francisco: Jossey-Bass.

[11] Dyer, W. W. (1993). Your erroneous zones. New York: Harper Paperbacks. Fanselow, 1987;

[12] Freeman, D. (1996). Redefining the relationship between research and what teachers know. In K.M. Bailey \& D. Nunan (eds.) Voices from the language classroom (pp. 88- 115). Cambridge: Cambridge University Press. 
[13] Gebhard, J. (1996). Teaching English as a foreign or second language. Ann Arbor: University of Michigan Press.

[14] Gebhard, J., \& R. Oprandy. (1999). Language teaching awareness: A guide to exploring beliefs and practices. New York: Cambridge University Press. Gergen, 2001

[15] Gergen, K. (2001). Self-narration in social life. In M. Wetherell, S. Taylor, \& S.J. Yates, (eds.), Discourse theory and practice: A reader (pp. 138-149). London: Sage.

[16] Hatch, J.A. (2002). Doing qualitative research in education settings. Albany, NY: State University of New York Press.

[17] Hinkel, E. (2001). Building awareness and practical skills to facilitate cross-cultural communication. In Marianne Celce-Murcia (ed.) Teaching English as a second or foreign language (pp. 443-458). Boston: Heinle\&Heinle.

[18] Kvale, S. (1996). InterViews. Thousand Oaks, CA:Sage.

[19] Lieblich, A., Tuval-Mashiach, R., \&Zilber, T. (1998) Narrative research: Reading, analysis, and interpretation. Thousand Oaks, CA: Sage.

[20] Lincoln. Y.S., \& Guba, E.G. (1985). Naturalistic Inquiry. Beverly Hills: Sage.

[21] Mishler, E.G. (1986). Research interviewing: Context and narrative. Cambridge, MA: Harvard University Press.

[22] Pagnucci, G. (2004). Living the narrative life: Stories as a tool for meaning making. Portsmouth, NH: Boynton/Cook.

[23] Paley, V.G. (1990). The boy who would be a helicopter: The uses of storytelling in the classroom. Cambridge, MA: Harvard University Press.

[24] Pavlenko, A. (2002). Narrative study: Whose story is it, anyway? TESOL Quarterly 36, 213-218.

[25] Pavlenko, A., \&Lantolf, J.P. (2000). Second language learning as participation and (re)construction of selves. In Lantolf, J.P.(ed.), Sociocultural theory and second Polkinghorne, D.E. (1988). Narrative knowing and the human sciences. Albany, NY:

[26] Polkinghorne, D.E. (1988). Narrative knowing and the human sciences. Albany, NY: SUNY Press.

[27] Rubin, H.J. and Rubin, I.S. (2005). Qualitative interviewing: The art of hearing data. Thousand Oaks, CA: Sage.

[28] Scollon, R. and S.W. Scollon. (1995). Intercultural communication, $2^{\text {nd }}$ ed. Malden, MA: Blackwell Publishers.

[29] Silverman, D. (2000). Analyzing talk and text. In N.K. Denzin \& Y.S. Lincoln (eds.) The handbook of qualitative research, $2^{\text {nd }}$ ed. (pp. 821-834). Thousand Oaks, CA: Sage.

[30] Spradley, J.P. (1979). The ethnographic interview. Belmont, CA: Wadsworth/Thomson Learning.

[31] Vandrick, S. (1999) ESL and the colonial legacy: A teacher faces her 'missionary kid' past. In G. HaroianGuerin (ed.) The personal narrative: Writing ourselves as teachers and scholars. (pp. 63-74). Portland, ME: Calendar Island Publishers.

[32] Woo, C.. (1999) Incarnating an Asian American angel: 'Self-expression,' ontology, and pedagogy. In G. Haroian-Guerin (ed.) The personal narrative: Writing ourselves as teachers and scholars. Portland, ME: Calendar Island Publishers.

\section{AUTHOR'S BIOGRAPHY}

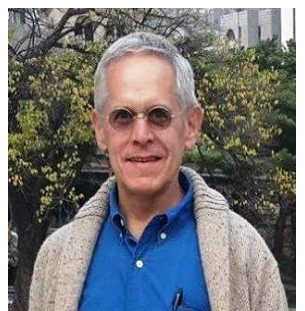

Jonny H. Bahk-Halberg, Ph.D., is an American writer and teacher based in Seoul since 1995. A former airplane mechanic, bartender, and journalist, he has been working for nearly two decades helping English interpreter-translators improve their language skills at Hankuk University of Foreign Studies. He is an associate professor in the College of English at HUFS, also teaching in the Graduate School of International and Area Studies. He also works as an adjunct associate professor with the University of Maryland University College - Asia, and as a speaking and writing examiner with University of Cambridge IELTS examinations.

Citation: Jonny H. Bahk-Halberg. "What's Your Story? Using Interviews and Narrative in Academic Research”. International Journal on Studies in English Language and Literature (IJSELL), vol 6, no.9, 2018, pp. 35-42. doi:http://dx.doi.org/10.20431/2347-3134.0609005.

Copyright: (C) 2018 Authors. This is an open-access article distributed under the terms of the Creative Commons Attribution License, which permits unrestricted use, distribution, and reproduction in any medium, provided the original author and source are credited. 